\title{
Joining of dissimilar materials by friction stir welding
}

\author{
Zakaria Boumerzoug ${ }^{1, *}$ \\ ${ }^{1}$ Department of Mechanical Engineering, Faculty of Science and Technology, University of Biskra, \\ BP145- 07000 Biskra, Algeria
}

\begin{abstract}
Welding is a process of joining materials into one piece. Welding is used extensively for pipe welding, aerospace, aviation, biomedical implants, fabrication of race cars, choppers, etc. Welding processes include thermal fusion joining processes and solid-state joining processes. Among solid-state joining processes, there is a friction stir welding which is applied to join two workpieces without materials. This technique of welding has great is used to weld dissimilar materials. This type of welding is gaining renewed interest, because the main objective is to reduce the total weight and maintaining essential physical properties. The objective of this paper is to focus on the friction stir welding of dissimilar materials.
\end{abstract}

\section{Welding of dissimilar materials}

The need of joining dissimilar materials often increases in industrial application due to demand for decreasing weight and improving performance. For example, decreasing vehicle weight is obtained by joining dissimilar metals such as welding steel to aluminum alloy. In industrial manufacturing, some parts are made by joining dissimilar materials such as metal with another metal, polymer with another polymer, or metal with another polymer. In the automobile and aerospace industry, some hybrid parts are made from lightweight dissimilar materials such as aluminum or magnesium alloys and fiberreinforced polymers [1-6].

Generally, the most used joining methods for dissimilar materials are mechanical fastening and adhesive bonding. Conventional welding processes based on fusion process, such as different arc welding techniques have been used to join some dissimilar metallic materials. However, the high energy input during arc welding limits its use for joining metal with polymer. Consequently, these traditional methods have their limits. For these reasons, new joining processes have been emerged such as electron beam welding, laser welding, ultrasonic welding, friction spot welding, and friction stir welding [1]. Friction stir welding (FSW) is one of the most processes used for joining different dissimilar materials. The objective of the development of the FSW was to reduce the common issues associated with other joining processes such as fusion welding, brazing and soldering etc.

\footnotetext{
*Corresponding author: zboumerzoug@yahoo.fr
} 
In the present review, the FSW technique, its advantages and disadvantages, and the main joined dissimilar materials by FSW are presented.

\section{Friction stir welding}

\subsection{Principle of FSW, types and its parameters}

Two friction welding processes are available, linear friction welding and rotary friction welding. In this paper, the linear friction welding or the friction stir welding (FSW) is presented. The FSW process was invented in 1991 by The Welding Institute (TWI) in the United Kingdom as a solid state joining process for joining aluminum alloys [7]. It is potentially a practicable joining process for similar and dissimilar materials. FSW is a solid state process during which a non-consumable rotating tool with a specially designed pin and shoulder is inserted into the abutting edges of sheets or plates to be joined and subsequently traversed along the joint line [8]. Heat is generated by the friction between the tool and the work pieces as well as the plastic deformation [9-13]. FSW is an ideal process for producing low cost and high performance joints. The practical approach of FSW is to use a non-consumable rotating tool consisting of two parts including a shoulder and a pin. Rotational speed of the tool, tool traverse speed, and vertical pressure on the plates during welding are the main process parameters of FSW [14].

However, the most convenient joint configurations for FSW are butt and lap joints. The FSW process with a lap joint configuration is the process in which, two lapped plates are clamped ( Fig.1.). A rotating tool is vertically plunged through the upper plate and partially into the lower plate and traversed along the desired direction joining the two plates. Figure 2 presents an example of welded dissimilar metals by FSW (steel with aluminum alloy).

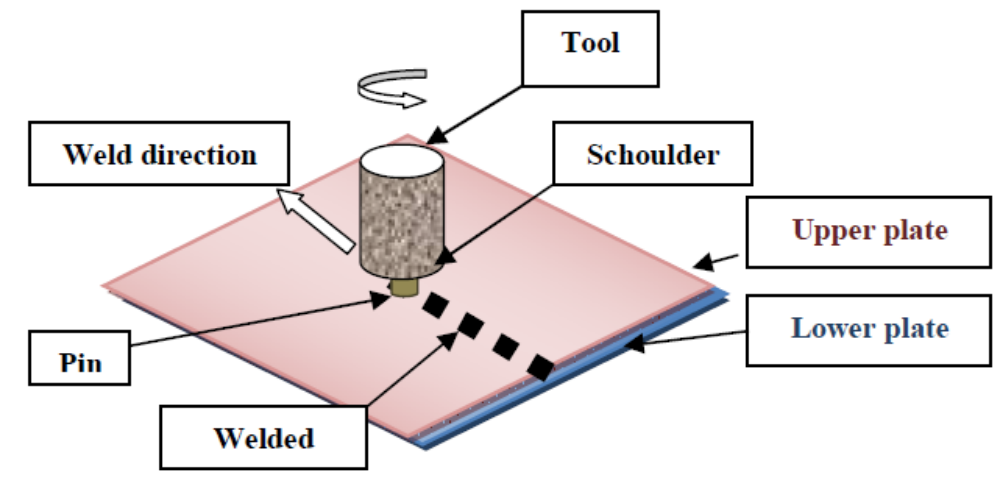

Fig. 1. Schematic representation of FSW process with a lap joint configuration. 


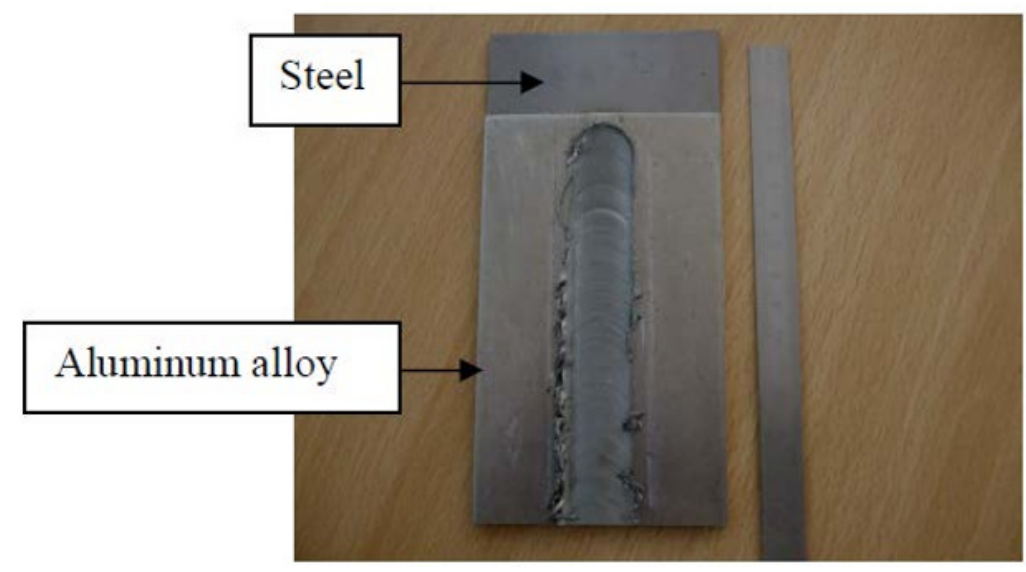

Fig. 2. Welded joint by FSW with lap joint configuration.

The FSW process with a lap butt configuration is the process in which a rotating tool is fed into a butt joint between clamped workpieces along the joint line ( Fig. 3).

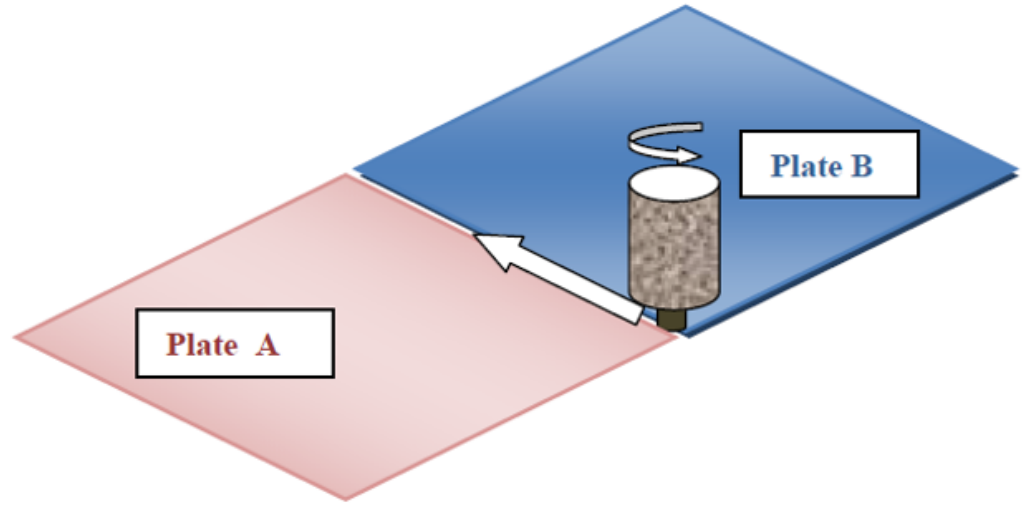

Fig. 3. Schematic representation of FSW process with a lap butt configuration.

The process parameters of FSW are classified into two main groups :

- Tooling related parameters: shoulder and pin material, shoulder diameter, pin length, pin diameter, feature geometry, thread pitch,

- Machine related parameters: welding speed, plunge force or depth, spindle speed, tool tilt angle, etc

In addition, other parameters can be considered such as anvil material, anvil size, workpiece size, workpiece properties, etc. [15].

From metallurgical aspect, the welded joint obtained by FSW exhibits four distinct zones, namely Base Metal ( BM), Heat Affected Zone ( HAZ), Thermo-mechanically Affected Zone ( TMAZ), and Stirred Zone ( SZ), also called Nugget Zone. The Stirred Zone is the region that experienced the highest strain and undergoes recrystallyzation. Its microstructure is due to mechanical action of the tool probe that generates a continuous dynamic recrystallization process. The highest temperature and the severe plastic deformation during the welding in the Stirred Zone result in a new equiaxed fine grain structure [16].

As example, an optical observation of a joint cross-section of an aluminum alloy to steel after welding by FSW with lap joint configuration is shown in Figure 4. The center of the 
joint exhibits the Stirred Zone ( called nugget zone). This stirred zone is the region that experienced the highest strain and undergoes recrystallyzation.

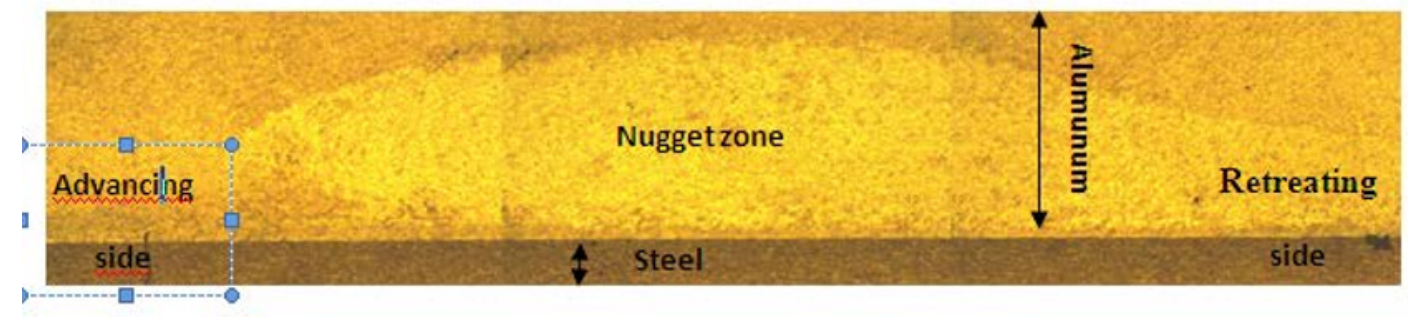

Fig. 4. Optical microscopy of welded joint by friction stir welding of aluminum alloy AL6061-T6 to ultra low carbon steel [17].

\subsection{Advantages and disadvantages of FSW}

As any process, the FSW has its advantages and disadvantages. The advantages of this technique are:

- Different types of joint like butt, lap, and T-joints can be welded successfully by FSW [18-20].

- Lower setup costs and less training [21].

- Easily automated on simple machine tools [21].

- Can operate in all positions (horizontal, vertical, etc), as there is no weld pool [21].

- Low environmental impact (no requirement of shielding gas, ecofriendly) [21].

- A lower welding temperature [22].

- Short welding time [22].

- Low porosity defect [23].

- Heat affected zone (HAZ) reduced[23].

- Reduced distorsion [23].

These advantages contribute to realize a welded joint with high mechanical properties.

However its disadvantages are :

- Exit holes are left when tool is withdrawn. [21].

- Difficulties with thickness variations [21].

\section{FSW applications}

\subsection{Joining of dissimilar metallic materials by FSW}

Most of the scientific investigation is focused on friction stir welding of aluminium, copper and magnesium [23]. This technique has been used for the first time to join aluminum alloys [7]. The welded joint is $90 \%$ defect free and without melting process of the workpiece as in case of fusion welding processes [7, 24 ]. After that, Thomas et al. [25] investigated the joining of steel by FSW. Liu et al. [26] studied the welded joint by FSW of copper with aluminum alloy and they found that no intermetallic compounds are observed in the stir zone. Chen and Nakata [27] also attempted FSW joining of aluminum with titanium. Table 1 presents the list of the most welded dissimilar metallic materials. 
Table 1. List of the welded dissimilar metallic materials by FSW.

\begin{tabular}{|l|}
\hline Welded dissimilar metalllic alloys by FSW \\
\hline $\mathrm{Al}$ alloy to steel \\
\hline $\mathrm{Al}$ alloy to magnesium alloy \\
\hline $\mathrm{Al}$ alloy to copper or copper alloy \\
\hline $\mathrm{Al}$ alloy to $\mathrm{Ti}$ or Ti alloy \\
\hline $\mathrm{Al}$ alloy to $\mathrm{Ag}$ \\
\hline $\mathrm{Mg}$ alloy to Ti alloy \\
\hline Steel to copper \\
\hline Steel to Ti or Ti alloy \\
\hline Coated steel to aluminum alloy \\
\hline
\end{tabular}

\subsection{Joining of dissimilar materials ( Hybrid materials) by FSW}

However, FSW has inspired researchers to join dissimilar materials ( Hybrid materials). In this context, a successful scientific works on welded joints of dissimilar materials by FSW have been published. These works were focused on joining of metal to polymer by FSW. The first published work appeared on 2012. This investigation is performed by Ratanathavorn et al. [28]. Nagatsuka et al. [29] joined by FSW of Aluminum alloy ( Al5052 ) to Carbon-fiber-reinforced plastic with lap joint configuration. Ratanathavorn et al. [30] studied the microstructures of dissimilar joint performed by FSW between aluminum alloy (AA 6111) and thermoplastic. Recently, Moshwan et al. [ 31] presented details about the microstructures of dissimilar joint between polycarbonate and AA 7075 aluminum alloy obtained by FSW. However, due to different material physiology and morphology, some difficulties faced researchers on microstructures characterization of metal/polymer joint. The main welded dissimilar ( Hybrid) materials are presented in Table 2.

Table 2. List of the welded dissimilar ( Hybrid) materials.

\begin{tabular}{|l|}
\hline Welded dissimilar materials by FSW \\
\hline copper/alumina \\
\hline Plastic- Metal \\
\hline
\end{tabular}

However, according to the content of the previous works on joining of dissimilar materials following points have not received enough attention and need to be studied:

- Most of the investigation is focused on friction stir welding of limited metallic materials and as aluminum, copper and magnesium and also to limited dissimilar materials as metal to polymer. FSW of alloys, plastics, composite materials, etc. is having huge scope for future research.

- The tribological corrosion and surface topographical behaviors of friction stir welded joints are not elaborately discussed in literature [23].

- No proper guideline in terms of mathematical theoretical model of process performance parameters of FSW is available for selecting parameters to obtain desired output [23].

\section{Conclusion}

On the basis of the review present above,

- FSW technique can be successfully applied to joining dissimilar materials.

- The practical approach of FSW is to use a non-consumable rotating tool.

- Many FSW parameters control the quality of the welded joint.

- The welded joint by FSW has high mechanical properties.

- FSW of alloys, plastics, composite materials, etc. is having huge scope for future research. 
- Many points have not received enough attention in the previous works and need to be studied in future investigation.

\section{References}

1. P. Kahn, R. Suoranta, J. Martikainen, C. Mgnus, Rev. Adv. Mater. Sci. 36 152-164 ( 2014)

2. C.E. Bakis, L.C. Bank, V.L. Brown, E. Cosenza, J,F. Davalos, J.J. Lesko, A. Machida, S.H. Rizkalla and T.C. Triantafilou, J. Compos. Constr. 673 ( 2002 )

3. W.S. Kim, I.I. Yun, J.J. Lee, H.T. Jung, Int. J. Adhes. 30408 ( 2010)

4. F. Balle, G. Wagner and D. Eifle, J. Adv. Eng. Mater. 111 ( 2009 )

5. Z. Sun, R. Karppi, J. Mater. Process. Technol. 59257 ( 1996)

6. A. Filho, S.T. Dos Santos, Polym. Eng. Sci. 49 1461( 2009 )

7. W. Thomas, E. Nicholas, J. Needham, M. Murch, P. Temple-Smith, and C. Dawes, International Patent No. PCT/GB92/02203, GB Patent No. 9125978, 1991, U.S. Patent No. 5,460,317, 1995, (1991)

8. R. S. Mishra, P. Sarathi De N. Kumar, Friction Stir Welding and Processing, Springer International Publishing Switzerland (2014)

9. Omar S. Salih, Hengan Ou,W. Sun, D.G. McCartney, Materials and Design 86 6171(2015)

10. RS. Mishra, ZY. Ma, Mater Sci Eng R: Rep. 50, 1-78, (2005).

11. T. DebRoy, HKDH. Bhadeshia, 15, 266-270 ( 2010)

12. R. Palanivel, P. Koshy Mathews, N. Murugan, I. Dinaharan, Mater Des , 40,716,(2012)

13. S. Rajakumar, V. Balasubramanian, Mater Des, 40,17-35 , (2012)

14. S. Rajakumar, C. Muralidharan, V. Balasubramanian, Journal of Engineering Manufacture, 224, pp. 1175-1191(2010)

15. D. Lohwasser, Z. Chen, Friction stir welding: from basics to applications, Woodhead Publishing limited, New Delhi ( 2010)

16. A.A. Hassan, A.F. Norman, D.A. Price, P.B. Prangnell, Acta Mater, 51, 19231936(2003).

17. Z. Boumerzoug, Y. Helal' $4^{\text {th }}$ International Conference on Welding Technologies andExhibition(ICWET'16)11-13 May 2016, Gaziantep-Turkey.

18. Y.N. Zhang, X. Cao, S. Larose, P. Wanjara, Can, Metall. Q. 51 (3) 250-261( 2012 )

19. R.S. Mishra, Z.Y. Ma, Mater. Sci. Eng. R. Rep. 50 (1-2) 1-78 ( 2005)

20. P. Threadgill, A. Leonard, H. Shercliff, P. Withers, Int. Mater. Rev. 54 ( 2 ) 49-93( 2009)

21. H.M. Anil Kumar, Dr. V. Venkata Ramana, Research Inventy: International Journal of Engineering and Science , 4, 6, 01-04 (2014)

22. T. Tanaka, T. Morishige, T. Hirata, Scripta Materialia 61 756-759 ( 2009)

23. S.M. Verma, J.P. Misra, A critical reviewof friction stir welding process, Chapter 22, DAAAM International Scientific Book, 249-266 (2015)

24. C. Dawes, W. Thomas, TWI Bulletin, 6, 124 ( 1995 )

25. W.M. Thomas, P.L. Threadgill, E.D. Nicholas, J. of Material Processing Technology, $178,342-349$ ( 1991) 
26. P. Liu, Q.Shi, W. Wang, X.Wang, Z. Zhang, Material and Design, 30, 469-474( 2008 )

27. Y. C. Chen, K. Nakata, Material and Design, 30, 469-474 ( 2009)

28. W. Ratanathavorn, Hybrid joining of aluminum to thermoplastics with friction stir welding, thesis (2012)

29. K. Nagatsuka, S. Yoshida, A. Tsuchiya, K. Nakata, Composites Part B: Engineering, 73, 82-88 (2015)

30. W. Ratanathavorn, A. Melander, 20, 222-8 (2015)

31. K. Moshvan, SM. Rahmat, F. Yusof, MA. Hassan, M. Fadzil, International Journal of Materials Research, 106, 258-66(2015) 